\title{
The Fetal Heart in Twin-to-Twin Transfusion Syndrome
}

\author{
Tim Van Mieghem, Liesbeth Lewi, Léonardo Gucciardo, Philip DeKoninck, \\ Dominique Van Schoubroeck, Roland Devlieger, and Jan Deprest
}

University Hospitals Leuven, Division of Woman and Child, Department of Obstetrics and Gynecology, Fetal Diagnosis and Therapy Unit, Herestraat 49, 3000 Leuven, Belgium

Correspondence should be addressed to Jan Deprest, jan.deprest@uzleuven.be

Received 9 March 2010; Accepted 12 July 2010

Academic Editor: Shinjiro Hirose

Copyright (C 2010 Tim Van Mieghem et al. This is an open access article distributed under the Creative Commons Attribution License, which permits unrestricted use, distribution, and reproduction in any medium, provided the original work is properly cited.

\begin{abstract}
Twin-to-twin transfusion syndrome is a severe complication occurring in $10 \%$ of monochorionic twin pregnancies. The disease is usually explained as due to an intrauterine imbalance in intertwin blood exchange, which leads to a volume depleted-donor twin and an overfilled recipient twin. The recipient has signs of cardiac dysfunction, which can be measured using echocardiography or blood and amniotic fluid derived biomarkers. Whereas cardiac dysfunction typically progresses in pregnancies treated with amniodrainage, it usually disappears within a few weeks after fetoscopic laser coagulation of the connecting intertwin anastomoses. Nevertheless, recipients remain at a increased risk of pulmonary stenosis. In this paper, we summarize the cardiac alterations in twin-to-twin transfusion syndrome, describe the changes seen after fetal therapy, list the newly proposed staging systems based on fetal cardiac function, and make recommendations about the use of fetal echocardiography in the evaluation and followup of pregnancies complicated by twin-to-twin transfusion syndrome.
\end{abstract}

\section{Introduction}

Monochorionic diamniotic twin pregnancies carry a 9\%$15 \%$ risk of developing twin-to-twin transfusion syndrome (TTTS) $[1,2]$. The pathophysiology of this disease is not fully understood, but the presence of vascular anastomoses connecting both fetal circulations at the level of the placenta is mandatory for its development. In carefully performed vascular injection studies, anastomoses have been documented in up to $95 \%$ of monochorionic placentas $[3,4]$, yet most of these pregnancies remain uncomplicated as the intertwin blood exchange is in balance. In a small subgroup however, the distribution of unidirectional arterial to venous anastomoses is imbalanced and an insufficient number of compensating bidirectional venovenous or arterio-arterial anastomoses is present, leading to a net shift of blood from one twin to the other $[5,6]$. The pathophysiology and therapy of twin-to-twin transfusion syndrome have recently been covered in an extensive review [7]. In brief, our current concept is that a net intertwin transfusion takes place over placental anastomoses, leading to volume shifts for which the fetuses cannot compensate. Additionally, plasma exchange and hormonal factors may play an important role in the disease. This ultimately results in a volume depleted donor twin, who will show signs of oligouria and oligohydramnios and a volume overloaded recipient twin who will present with polyuria and polyhydramnios. The diagnosis of TTTS is based on strict sonographic criteria reflecting severe intertwin fluid discordance. The criteria for TTTS are met when the deepest vertical amniotic fluid pocket is $2 \mathrm{~cm}$ or less in the donors amniotic sac. In Europe, gestational agedependent criteria are used to define the polyhydramnios in the recipient twin (a deepest amniotic fluid pocket of more than $8 \mathrm{~cm}$ prior to 20 weeks and more than $10 \mathrm{~cm}$ after 20 weeks), whereas in the United States the $8 \mathrm{~cm}$ cutoff is used throughout gestation. The disease is currently staged based on the "Quintero system" which takes in account the filling of the bladder in the donor (stage I if the bladder is seen on ultrasound, stage II if not), the presence of arterial or venous Doppler flow abnormalities (stage III), the presence of fetal hydrops (stage IV) and intrauterine fetal demise (stage V) [8]. When left untreated, TTTS has a mortality 
and morbidity of up to $90 \%$, mainly due to preterm rupture of the membranes and miscarriage or severe preterm birth as a result of the massive polyhydramnios [9]. However, intrauterine demise of one or both fetuses due to severe cardiac failure can also occur [10]. Treatment of severe midtrimester TTTS has shifted over the last 10 years from (repetitive) amniodrainage to fetoscopic laser coagulation of the connecting placental vessels. The latter therapy interrupts the intertwin transfusion and has been shown to improve neonatal survival and to decrease infant morbidity when compared to amniodrainage in a randomized trial $[11,12]$.

Although different research groups have focused on this disease and the number of publications on TTTS has risen exponentially over the last years, we still do not understand the exact nature of the disease [7]. Consequently, the currently used staging system does not describe the natural evolution of the disease, nor does it predict individual fetal survival after laser surgery adequately. Other insufficiently answered clinical questions are the prediction of the disease [13-16] and the optimal therapy for early (stage I) disease (expectant management, amniodrainage, laser) [17].

In an attempt to address the above questions, and with the advent of more sophisticated imaging tools in fetal cardiology [18], fetal medicine specialists and cardiologists have turned to comprehensive examination of the recipients heart. Indeed, one could expect volume shifts towards the recipient to be reflected in progressive cardiac failure. Consequently, a staging system based on the recipients cardiac function would make sense from a pathophysiological point of view and cardiac function assessment could theoretically be used for predicting the disease and for predicting recipient fetus survival after laser therapy.

This paper will update the reader on the fetal cardiac findings in TTTS and will discuss the indications of fetal echocardiography in TTTS.

\section{Echocardiographic Findings in TTTS}

2.1. Recipient Fetuses. Up to $70 \%$ of recipient fetuses of TTTS show some echocardiographic sign of cardiac compromise at the time of diagnosis [19], either at the anatomical or at the functional level. As such, in about half the cases, the heart is enlarged [20-22] due to an increased myocardial thickness [23] rather than to ventricular dilatation [10, 24]. In terms of systolic function, shortening fraction is considerably decreased in $30 \%$ of the recipients [10, 21, 22], and this predominantly at the level of the right ventricle [10]. Accordingly, speckle-tracking-derived measurements of strain and strain rate, although difficult to perform, show decreased strain in the right ventricle of recipient fetuses of TTTS [25]. In contrast to the lower contractility and to earlier reports that did not show differences in cardiac output between donors and recipients [22, 26], two recent series in relatively large cohorts of recipient fetuses have shown a moderate increase in cardiac output when corrections were made for fetal weight $[23,27]$. This finding clearly fits in with the volume overload theory.
In TTTS, diastolic function is even more compromised than systolic function. As a consequence of the thickened, dysfunctional myocardium, monophasic ventricular filling patterns such as those seen in restrictive cardiomyopathy occur in about $20 \%-30 \%$ of cases, again with a predominance on the right side [21, 28]. Moreover, we often observe a shortening of the ventricular filling time [29], a prolongation of the isovolumetric relaxation time [30] and an increase in the Tei-index (which is a geometry independent indicator of both systolic and diastolic function based on the assessment of the isovolumetric relaxation and the isovolumetric contraction time $[31,32])$. On average, the Tei-index is $40 \%$ higher than normal $[23,30,33]$ and values above the upper limit of normal are observed in about $50 \%$ of cases $[24,28,30]$. Interpretation of the Teiindex in the fetal setting nevertheless deserves particular caution as fetal blood pressure is often unknown and prolongation of the isovolumetric contraction time can be a reflection of hypertension rather than of systolic dysfunction. Therefore, separate analysis of the isovolumetric contraction and relaxation time is justified, yet only technically possible at the level of the left ventricle due to the implantation of the pulmonary and tricuspid valve precluding simultaneous recording of the pulmonary and tricuspid flow.

Tricuspid regurgitation occurs in about $30 \%-50 \%$ of recipients $[21,28,34]$ but is severe in only half of these $[10,21-23]$. Mitral regurgitation on the other hand is much less frequent ( $6 \%-14 \%$ of cases) $[21,28]$, yet usually severe (9\%) [21]. The presence of valvular regurgitation allows to estimate fetal blood pressure using the Bernouilli equation and studies have shown that recipient fetuses display marked hypertension with systolic pressures over 2-fold the normal value for gestational age [35].

Further down the vascular tree, Doppler assessment of the ductus venosus and the umbilical venous flow allows to estimate the right atrial pressure curve. Reversed flow in the ductus venosus and umbilical vein pulsations have been integrated in the Quintero staging system and their presence upstages the disease to stage III. In most series from tertiary referral centers, abnormal ductus venosus dopplers are seen in about 1 in 3 recipients $[21,23,28,34]$ and a pulsatile umbilical vein in 1 in 10 [21, 22, 28].

A summary of the fetal echo findings in a prospective series of 78 consecutive cases seen in our unit is presented in Table 1 (unpublished data). It is important to note that in Quintero stage I, already $45 \%$ of cases show signs of ventricular dysfunction in terms of an increased Tei index and that $35 \%$ of cases have a fused right ventricular inflow pattern suggestive of diastolic dysfunction. The occurrence of these so-called early findings remains relatively stable over stage I to III, similar to what has been published earlier [24].

Nevertheless, other findings such as the left ventricular Tei-index and mitral and tricuspid regurgitation increase with Quintero stage [21] suggesting that the Quintero staging system, at least to some degree, reflects progressive fetal cardiovascular compromise.

Our group has shown that changes in cardiac function are already present well before the actual development of TTTS. As such, about 30\% of fetuses with moderate amniotic 
TABLE 1: Occurence of cardiac function alterations in 78 consecutive recipient fetuses assessed at the University Hospitals Leuven, Belgium.

\begin{tabular}{|c|c|c|c|c|c|}
\hline & Stage I $(n=11)$ & Stage II $(n=19)$ & Stage III $(n=42)$ & Stage IV $(n=6)$ & Overall $(n=78)$ \\
\hline $\begin{array}{l}\text { Reversed a-wave ductus } \\
\text { venosus }(\%)\end{array}$ & 0 & 0 & 62 & 50 & 37 \\
\hline Umbilical vein pulsations (\%) & 0 & 0 & 50 & 67 & 32 \\
\hline Fusion of RV inflow (\%) & 36 & 37 & 38 & 83 & 41 \\
\hline Tricuspid regurgitation (\%) & 9 & 21 & 38 & 67 & 31 \\
\hline $\begin{array}{l}\text { RV-MPI > percentile } \\
97.5(\%)\end{array}$ & 45 & 47 & 48 & 83 & 49 \\
\hline Fusion of LV inflow (\%) & 9 & 21 & 29 & 67 & 27 \\
\hline Mitral regurgitation (\%) & 0 & 0 & 10 & 50 & 10 \\
\hline $\begin{array}{l}\text { LV-MPI > percentile } \\
97.5(\%)\end{array}$ & 25 & 42 & 38 & 83 & 41 \\
\hline
\end{tabular}

RV: right ventricle, LV: left ventricle, and MPI: myocardial performance index.

fluid discordance not fulfilling the criteria of TTTS but ultimately progressing to the syndrome show an increased myocardial performance index [36]. Along the same line, $40 \%$ of monochorionic twins that ultimately will develop TTTS have already abnormal findings in the ductus venosus flow $[1,13]$ or discordant nuchal translucency measurements reflective of altered hemodynamics in the first trimester of pregnancy $[14,15,37]$. Unfortunately, these findings are not very specific, nor very sensitive. They cannot therefore be used for early prediction of the disease, nor should they be used to "upstage" (often benign) fluid discordance to TTTS.

Once a TTTS is fully installed, echocardiographic findings tend to progress over time, with worsening ventricular hypertrophy and systolic dysfunction, which can ultimately lead to fetal hydrops and intrauterine fetal demise [38]. Moreover, as growth of fetal cardiac structures is dependent on the blood flow through them, persistent ventricular dysfunction can lead to secondary anatomic changes. Consequently, in a consecutive series of 150 recipient fetuses, $16 \%$ had a smaller than expected right ventricular outflow tract at the time of initial presentation [21]. In up to $4 \%$, extreme right ventricular dysfunction can result in functional pulmonary atresia (Figure 1) with retrograde perfusion of the pulmonary trunk through the ductus arteriosus $[10,34]$ and more rarely even in complete right heart flow reversal [39].

2.2. Donor Fetuses. In contrast to recipient fetuses, donors seem to have a normal cardiac function, yet some $5 \%-10 \%$ present with abnormal Doppler waveforms in the ductus venosus, and 3\% with tricuspid regurgitation or umbilical vein pulsations $[34,40]$, findings which are generally explained by the presence of severe placental insufficiency. The latter is also supported by an increased occurrence of abnormal diastolic flow in the umbilical artery in the donor fetus.

Furthermore, although not significant in most studies, the donor twin has a trend towards a lower Tei-index than in the normal population which is suggestive of hypotension $[27,40]$. Finally, there have been speculations about an increased incidence of aortic coarctation in donors due to a lower venous return from the placenta and hence a decreased loading of the left ventricular outflow tract [41].

\section{Biomarkers of Altered Fetal Hemodynamics in TTTS}

Different vasoactive peptides have been investigated in TTTS, mainly in an attempt to further explain the underlying pathophysiological mechanisms.

The renin angiotensin aldosterone system has been found to be upregulated in the donor kidney [42]. Transfer of these hormones towards the recipient through the placental anastomoses partly explains the hypertension (angiotensin II) and the hypervolemia (aldosterone) seen in this fetus. Additional upregulation of atrial natriuretic factor (ANF) has been observed in recipients when compared to donor fetuses [43]. Plasma levels of ANF are correlated with the amount of amniotic fluid yet not with the severity of cardiac dysfunction [43] and are therefore thought to mediate the recipients polyuria.

Increased endothelin-1 [44], brain or b-type natriuretic peptide (BNP) [28, 44, 45] and cardiac troponin T [28] levels have been observed in the plasma and/or the amniotic fluid of recipient fetuses, similar to observations in adults with chronic heart failure. Endothelin-1 can certainly play a role in the development of the severe hypertension [35, 44], stimulates the myocardial remodeling [46] and could decrease cardiac function. The presence of both BNP and cardiac troponin $\mathrm{T}$ [28] suggests that the myocardium is not only stretched by the volume load but also that it undergoes structural damage/remodeling.

\section{New Staging Systems in TTTS}

In an attempt to provide a more pathophysiologic classification of TTTS [47], different groups have suggested to use new staging systems that are mainly based on the severity of cardiac dysfunction in the recipient fetus. The most extensive system has been elaborated by the Children's Hospital Of Philadelphia (CHOP) [21] and requires the evaluation of 12 


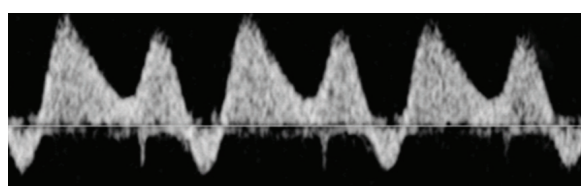

(a)

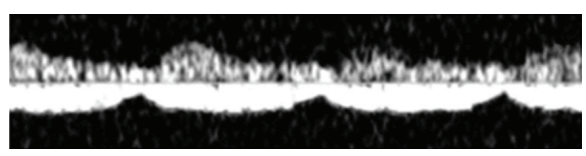

(b)

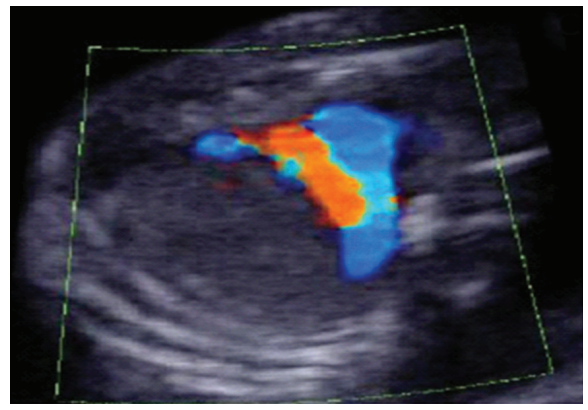

(c)

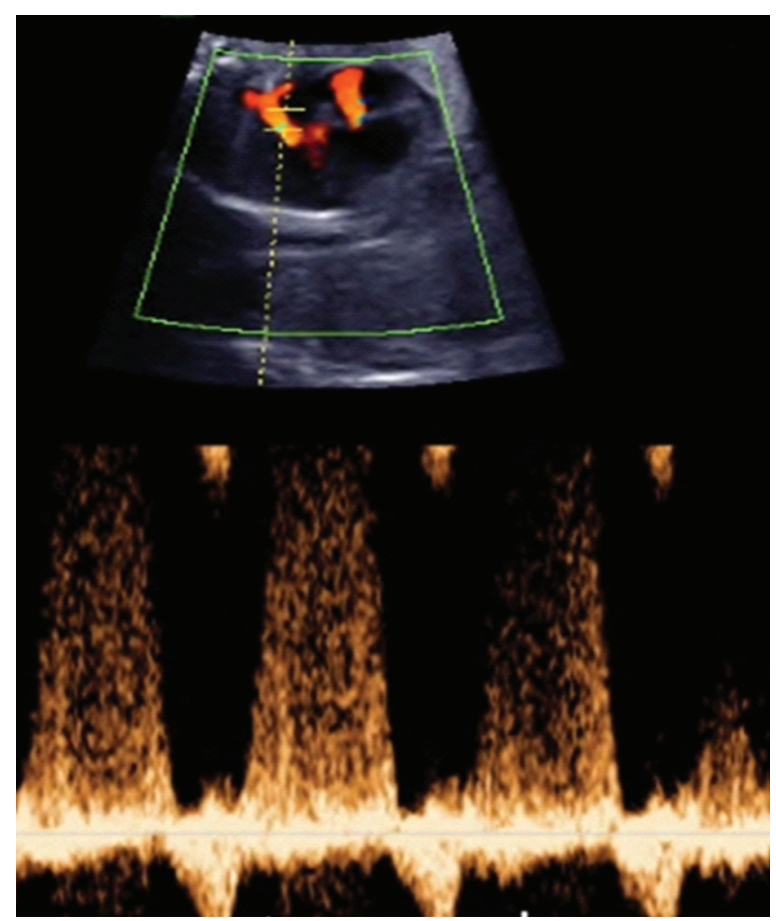

(d)

FIGURE 1: Common echocardiographic findings in the recipient of TTTS. (a) Reversed flow in the ductus venosus. (b) Umbilical vein pulsations. (c) Transverse view of the fetal chest at the level of the 3-vessel view demonstrating forward flow in the aorta (blue) and reversed flow in the ductus arteriosus and pulmonary artery (red) suggestive of functional pulmonary atresia. (d) Doppler assessment at the level of the fetal 4-chamber view demonstrating mitral and tricuspid regurgitation with the corresponding pulsed Doppler spectrum below.

variables which, in experienced hands, takes 30-45 minutes per fetus and is therefore not feasible in routine clinical practice (Table 2). Also, different parameters of cardiac function are correlated. For example, we have shown that the ejection fraction correlates with the myocardial performance index [33] and others demonstrated that abnormal flow in the ductus venosus correlates with tricuspid regurgitation [34]. Finally, Rychik et al. [21] showed that the right ventricular Tei-index was strongly correlated with their full 12 parameter score, suggesting that the creation of an easier staging system, still encompassing the full extent of the disease should be feasible.

Going further into this, Stirnemann et al. [23] used cluster analysis and partitioning algorithms to determine that a staging system including only the assessment of the left and right ventricular myocardial performance index allows to stratify cases as well as a system with additional inclusion of shortening fractions, ductus venosus pulsatility index and cardiac output. A comparison of the anatomic and functional parameters in the different proposed "cardiac" staging systems is presented in Table 2 .

At present, we do not feel that these new staging systems should replace the Quintero system, which is an easy and widely accepted method for patient stratification that has proven some usefulness in terms of predicting fetal outcome after laser therapy $[11,49]$. Nevertheless, cardiac staging systems may play an important role in the further understanding of the pathophysiology of the disease and are useful in research settings.

\section{Effect of Prenatal Therapy}

Amniodrainage usually does not cure TTTS but is rather a palliative and repetitive intervention aimed at relieving the polyhydramnios. As such, it does not improve fetal cardiac function and fetuses undergoing repetitive amniodrainage show progressive cardiac disease and hydrops and are at risk for intrauterine demise $[10,50]$.

On the other hand, closure of the vascular anastomoses at the level of the placenta and functional separation of both fetuses by fetoscopic laser leads to a rapid improvement in cardiac function in the recipient fetus. Already in the first 48 hours after therapy, cardiac size, precordial venous Dopplers, valvular regurgitation, and ventricular inflow patterns normalize in about half of the cases and the Tei-index improves with approximately $40 \%[19,20,40$, 51]. Survival is worse in fetuses lacking this functional improvement immediately after surgery [19]. In the longer term, further amelioration in cardiac function continues and approximately 6 weeks after therapy most cases have regained normal cardiac function [40]. The normalization of cardiac dysfunction is very similar to, but slightly faster than, what is seen in neonates delivered at the time of TTTS 
TABLE 2: Comparison of the cardiac parameters assessed in the different proposed staging systems.

\begin{tabular}{|c|c|c|c|c|c|}
\hline & Quintero et al. 1999 [8] & Rychik et al. 2007 [21] & Shah et al. 2008 [48] & Habli et al. 2008 [19] & $\begin{array}{l}\text { Stirnemann et al. } \\
2010 \text { [23] }\end{array}$ \\
\hline & & "CHOP-score" & $\begin{array}{l}\text { "Cardiovascular } \\
\text { profile score" }\end{array}$ & “Cincinatti staging" & \\
\hline Cardiothoracic ratio & & $\mathrm{x}$ & $\mathrm{x}$ & & \\
\hline Ventricular wall thickness & & $\mathrm{x}$ & & $\mathrm{x}$ & \\
\hline Shortening fraction & & $\mathrm{x}$ & $\mathrm{x}$ & & \\
\hline Tei-index right ventricle & & & & $\mathrm{x}$ & $\mathrm{x}$ \\
\hline Tei-index left ventricle & & & & $\mathrm{x}$ & $\mathrm{x}$ \\
\hline $\mathrm{AV}$ regurgitation & & $\mathrm{x}$ & $\mathrm{x}$ & $\mathrm{x}$ & \\
\hline AV inflow & & $\mathrm{x}$ & & & \\
\hline Pulmonary insufficiency & & $\mathrm{x}$ & & & \\
\hline Outflow tract size & & $\mathrm{x}$ & & & \\
\hline Ductus venosus & $\mathrm{x}$ & $\mathrm{x}$ & $\mathrm{x}$ & $\mathrm{x}$ & \\
\hline Umbilical vein & $\mathrm{x}$ & $\mathrm{x}$ & $\mathrm{x}$ & $\mathrm{x}$ & \\
\hline Hydrops & $\mathrm{x}$ & & $\mathrm{x}$ & $\mathrm{x}$ & \\
\hline Umbilical artery donor & $\mathrm{x}$ & $\mathrm{x}$ & $\mathrm{x}$ & $\mathrm{x}$ & \\
\hline
\end{tabular}

AV: ventricular valve.

[52]. Interestingly, even severe cardiac dysfunction such as functional pulmonary atresia and hydrops resolve in almost all cases $[51,53]$, which argues against the use of selective reduction in these fetuses.

In contrast to recipients, about 1 in 4 donor fetuses has a temporary worsening in cardiac function with increased cardiac size [20], tricuspid regurgitation, ductus venosus alterations, and subcutaneous oedema $[34,40,54]$ after fetoscopic laser therapy. These findings however disappear by $2-$ 4 weeks after the surgery $[40,54]$ and are probably explained by the sudden arrest of the transfusion imbalance and temporary relative volume overload in the former donor fetus.

Different groups have investigated whether fetal demise after laser therapy (which occurs in about $18 \%$ of recipient fetuses [49]) can be predicted by preoperative fetal cardiac function. In a retrospective series, Shah and colleagues showed that recipient cardiovascular profile score can predict outcome to a certain extent [48]. In line with this finding, we have shown that recipient fetuses with a normal Teiindex and low amniotic fluid cardiac troponin $\mathrm{T}$ levels have an improved survival compared to those with alterations in either of these 2 parameters. However, cardiac function alone does not predict outcome [28], as confirmed in a larger multicenter series including more than 200 TTTS cases [55]. This is explained by the fact that fetal demise after laser is multifactorial and also depends on other factors such as placental sharing or incomplete laser separation. For clinical practice, it means that for now, fetal therapy cannot be tailored to the individual situation based on fetal cardiac function assessment.

\section{Long Term Cardiac Outcome after TTTS}

Followup until the age of 10 year has shown that both donors and recipients of nonlasered TTTS have normal cardiac func- tion in the longer term [56]. Recipient twins nevertheless maintain a slightly reduced early diastolic ventricular filling as compared to donors (diastolic dysfunction). Donors on the other hand seem to have higher arterial wall stiffness than recipients, suggestive of intrauterine vascular programming [57]. Fetoscopic laser therapy can alter this prenatal vascular programming. As such, fetuses that underwent laser have normal wall stiffness and normal cardiac function at the age of 2 year [58, 59]. However, the increased occurrence of right ventricular outflow tract obstruction observed at the time of TTTS (16\%) [21] does not disappear completely and recipient fetuses remain at a 3 -fold increased risk (5\%-8\%) of pulmonary stenosis at the time of birth when compared to uncomplicated monochorionic twins $[22,59]$.

\section{Clinical Recommendations}

In clinical practice, the main question remains whether (functional) fetal echocardiography should be used in the evaluation and follow-up of pregnancies complicated with TTTS and if the answer is yes, when echocardiography should be performed. From the above listed data, we feel that the only clinically useful echocardiographic finding in TTTS pregnancies booked for fetoscopic laser therapy is the presence of persistent pulmonary artery stenosis after therapy which would impact on the place of delivery and on postnatal management. As a result, we would recommend a thorough (structural) cardiac evaluation 8-10 weeks after the fetoscopic surgery, when cardiac dysfunction has completely resolved, to assess pulmonary artery development and to plan the site of delivery.

In TTTS pregnancies managed expectantly or undergoing (repetitive) amniodrainage, the evidence is less clear, yet we feel they should undergo intensive cardiac follow-up with at least assessment of ductus venosus and umbilical vein flow 
and evaluation for the presence of hydrops to time eventual delivery or to switch therapy to laser before intrauterine fetal demise occurs. Additionally, these fetuses should undergo evaluation for pulmonary artery stenosis before birth.

As all recipient fetuses of TTTS, both managed conservatively or with laser, are at increased risk of pulmonary artery stenosis, we are convinced that an early postnatal screening echocardiogram is indicated. Moreover, because all monochorionic twins are at increased risk for structural cardiac abnormalities compared to singletons or dichorionic twins [22], all should benefit from midtrimester structural echocardiographic assessment

\section{Conclusions and Future Perspectives}

In summary, cardiac dysfunction is a common finding in recipient fetuses and different new "cardiac" staging systems have been proposed. Although they may bring new pathophysiologic insights, their clinical value remains limited as they do not predict the occurrence nor the outcome of the disease. However, further evaluation is necessary in stage I disease, where equipoise is still present about the optimal treatment strategy [17]. Additionally, the impact of the decreased cardiac function on cerebral perfusion and longterm neurologic development requires further investigation. Fetoscopic laser coagulation of the vascular anastomoses interrupts the intertwin transfusion and has been shown to lead to fast normalization of cardiac function. Nevertheless, recipients remain at increased risk of pulmonary artery stenosis. Further work should be directed at detecting prenatally which twins will have clinically important lesions at the time of birth.

\section{Acknowledgments}

This work was supported by the Belgian Flemish Community who partially funds our clinical program (no. IWT/070715) and the doctoral fellowship of T. V. Mieghem. J. Deprest is a clinical researcher for the Fonds voor Wetenschappelijk Onderzoek Vlaanderen (no. 1.8.012.07.N.02).

\section{References}

[1] L. Lewi, J. Jani, I. Blickstein et al., "The outcome of monochorionic diamniotic twin gestations in the era of invasive fetal therapy: a prospective cohort study," American Journal of Obstetrics and Gynecology, vol. 199, no. 5, pp. 514.e1-514.e8, 2008.

[2] N. J. Sebire, A. Souka, H. Skentou, L. Geerts, and K. H. Nicolaides, "Early prediction of severe twin-to-twin transfusion syndrome," Human Reproduction, vol. 15, no. 9, pp. 20082010, 2000.

[3] L. Lewi, M. Cannie, I. Blickstein et al., "Placental sharing, birthweight discordance, and vascular anastomoses in monochorionic diamniotic twin placentas," American Journal of Obstetrics and Gynecology, vol. 197, no. 6, pp. 587.e1-587.e8, 2007.
[4] K. E. A. Hack, P. G. J. Nikkels, C. Koopman-Esseboom et al., "Placental characteristics of monochorionic diamniotic twin pregnancies in relation to perinatal outcome," Placenta, vol. 29, no. 11, pp. 976-981, 2008.

[5] M. L. Denbow, P. Cox, M. Taylor, D. M. Hammal, and N. M. Fisk, "Placental angioarchitecture in monochorionic twin pregnancies: relationship to fetal growth, fetofetal transfusion syndrome, and pregnancy outcome," American Journal of Obstetrics and Gynecology, vol. 182, no. 2, pp. 417-426, 2000.

[6] M. L. Denbow, P. Cox, D. Talbert, and N. M. Fisk, "Colour Doppler energy insonation of placental vasculature in monochorionic twins: absent arterio-arterial anastomoses in association with twin-to-twin transfusion syndrome," British Journal of Obstetrics and Gynaecology, vol. 105, no. 7, pp. 760765, 1998.

[7] N. M. Fisk, G. J. Duncombe, and M. H. F. Sullivan, "The basic and clinical science of twin-twin transfusion syndrome," Placenta, vol. 30, no. 5, pp. 379-390, 2009.

[8] R. A. Quintero, W. J. Morales, M. H. Allen, P. W. Bornick, P. K. Johnson, and M. Kruger, "Staging of twin-twin transfusion syndrome," Journal of Perinatology, vol. 19, no. 8, pp. 550-555, 1999.

[9] V. Berghella and M. Kaufmann, "Natural history of twin-twin transfusion syndrome," Journal of Reproductive Medicine for the Obstetrician and Gynecologist, vol. 46, no. 5, pp. 480-484, 2001.

[10] C. Barrea, F. Alkazaleh, G. Ryan et al., "Prenatal cardiovascular manifestations in the twin-to-twin transfusion syndrome recipients and the impact of therapeutic amnioreduction," American Journal of Obstetrics and Gynecology, vol. 192, no. 3, pp. 892-902, 2005.

[11] M.-V. Senat, J. Deprest, M. Boulvain, A. Paupe, N. Winer, and Y. Ville, "Endoscopic laser surgery versus serial amnioreduction for severe twin-to-twin transfusion syndrome," The New England Journal of Medicine, vol. 351, no. 2, pp. 136-144, 2004.

[12] R. Lenclen, G. Ciarlo, A. Paupe, L. Bussieres, and Y. Ville, "Neurodevelopmental outcome at 2 years in children born preterm treated by amnioreduction or fetoscopic laser surgery for twin-to-twin transfusion syndrome: comparison with dichorionic twins," American Journal of Obstetrics and Gynecology, vol. 201, no. 3, pp. 291.e1-291.e5, 2009.

[13] N. Maiz, I. Staboulidou, A. M. Leal, R. Minekawa, and K. H. Nicolaides, "Ductus venosus Doppler at 11 to 13 weeks of gestation in the prediction of outcome in twin pregnancies," Obstetrics and Gynecology, vol. 113, no. 4, pp. 860-865, 2009.

[14] K. O. Kagan, A. Gazzoni, G. Sepulveda-Gonzalez, A. Sotiriadis, and K. H. Nicolaides, "Discordance in nuchal translucency thickness in the prediction of severe twin-to-twin transfusion syndrome," Ultrasound in Obstetrics and Gynecology, vol. 29, no. 5, pp. 527-532, 2007.

[15] A. Matias, N. Montenegro, T. Loureiro et al., "Screening for twin-twin transfusion syndrome at 11-14 weeks of pregnancy: the key role of ductus venosus blood flow assessment," Ultrasound in Obstetrics and Gynecology, vol. 35, no. 2, pp. 142-148, 2010.

[16] L. Lewi, P. Lewi, A. Diemert et al., "The role of ultrasound examination in the first trimester and at 16 weeks' gestation to predict fetal complications in monochorionic diamniotic twin pregnancies," American Journal of Obstetrics and Gynecology, vol. 199, no. 5, pp. 493.e1-493.e7, 2008.

[17] S. Molina, R. Papanna, K. J. Moise Jr., and A. Johnson, "Management of stage I twin-to-twin transfusion syndrome: an international survey," Ultrasound in Obstetrics and Gynecology, vol. 36, no. 1, pp. 42-47, 2010. 
[18] T. Van Mieghem, P. DeKoninck, P. Steenhaut, and J. Deprest, "Methods for prenatal assessment of fetal cardiac function," Prenatal Diagnosis, vol. 29, no. 13, pp. 1193-1203, 2009.

[19] M. Habli, E. Michelfelder, J. Livingston et al., "Acute effects of selective fetoscopic laser photocoagulation on recipient cardiac function in twin-twin transfusion syndrome," American Journal of Obstetrics and Gynecology, vol. 199, no. 4, pp. 412.e1-412.e6, 2008.

[20] M. Sueters, J. M. Middeldorp, F. P. H. A. Vandenbussche et al., "The effect of fetoscopic laser therapy on fetal cardiac size in twin-twin transfusion syndrome," Ultrasound in Obstetrics and Gynecology, vol. 31, no. 2, pp. 158-163, 2008.

[21] J. Rychik, Z. Tian, M. Bebbington et al., "The twin-twin transfusion syndrome: spectrum of cardiovascular abnormality and development of a cardiovascular score to assess severity of disease," American Journal of Obstetrics and Gynecology, vol. 197, no. 4, pp. 392.e1-392.e8, 2007.

[22] A. A. Karatza, J. L. Wolfenden, M. J. O. Taylor, L. Wee, N. M. Fisk, and H. M. Gardiner, "Influence of twin-twin transfusion syndrome on fetal cardiovascular structure and function: prospective case-control study of 136 monochorionic twin pregnancies," Heart, vol. 88, no. 3, pp. 271-277, 2002.

[23] J. J. Stirnemann, M. Mougeot, F. Proulx et al., "Profiling fetal cardiac function in twin-twin transfusion syndrome," Ultrasound in Obstetrics and Gynecology, vol. 35, no. 1, pp. 1927, 2010.

[24] E. Michelfelder, W. Gottliebson, W. Border et al., "Early manifestations and spectrum of recipient twin cardiomyopathy in twin-twin transfusion syndrome: relation to Quintero stage," Ultrasound in Obstetrics and Gynecology, vol. 30, no. 7, pp. 965-971, 2007.

[25] T. Van Mieghem, S. Giusca, P. DeKoninck et al., "Prospective assessment of fetal cardiac function with speckle tracking in healthy fetuses and recipient fetuses of twin-to-twin transfusion syndrome," Journal of the American Society of Echocardiography, vol. 23, no. 3, pp. 301-308, 2010.

[26] M. Sueters, J. M. Middeldorp, E. Lopriore et al., "Fetal cardiac output in monochorionic twins," Ultrasound in Obstetrics and Gynecology, vol. 32, no. 6, pp. 807-812, 2008.

[27] A. Szwast, Z. Tian, M. McCann et al., "Impact of altered loading conditions on ventricular performance in fetuses with congenital cystic adenomatoid malformation and twintwin transfusion syndrome," Ultrasound in Obstetrics and Gynecology, vol. 30, no. 1, pp. 40-46, 2007.

[28] T. Van Mieghem, E. Doné, L. Gucciardo et al., "Amniotic fluid markers of fetal cardiac dysfunction in twin-to-twin transfusion syndrome," American Journal of Obstetrics and Gynecology, vol. 202, pp. 48.e1-48.e7, 2010.

[29] B. Bensouda, J.-C. Fouron, M.-J. Raboisson, J. Lamoureux, C. Lachance, and L. Leduc, "Relevance of measuring diastolic time intervals in the ductus venosus during the early stages of twin-twin transfusion syndrome," Ultrasound in Obstetrics and Gynecology, vol. 30, no. 7, pp. 983-987, 2007.

[30] M. J. Raboisson, J. C. Fouron, J. Lamoureux et al., "Early intertwin differences in myocardial performance during the twin-to-twin transfusion syndrome," Circulation, vol. 110, no. 19, pp. 3043-3048, 2004.

[31] T. Tsutsumi, M. Ishii, G. Eto, M. Hota, and H. Kato, "Serial evaluation for myocardial performance in fetuses and neonates using a new Doppler index," Pediatrics International, vol. 41, no. 6, pp. 722-727, 1999.
[32] C. Tei, L. H. Ling, D. O. Hodge et al., "New index of combined systolic and diastolic myocardial performance: a simple and reproducible measure of cardiac function-a study in normals and dilated cardiomyopathy," Journal of Cardiology, vol. 26, no. 6, pp. 357-366, 1995.

[33] T. Van Mieghem, L. Gucciardo, P. Lewi et al., "Validation of the fetal myocardial performance index in the second and third trimesters of gestation," Ultrasound in Obstetrics and Gynecology, vol. 33, no. 1, pp. 58-63, 2009.

[34] L. Zikulnig, K. Hecher, T. Bregenzer, E. Bäz, and B. J. Hackelöer, "Prognostic factors in severe twin-twin transfusion syndrome treated by endoscopic laser surgery," Ultrasound in Obstetrics and Gynecology, vol. 14, no. 6, pp. 380-387, 1999.

[35] D. Mahieu-Caputo, L. J. Salomon, J. Le Bidois et al., "Fetal hypertension: an insight into the pathogenesis of the twintwin transfusion syndrome," Prenatal Diagnosis, vol. 23, no. 8, pp. 640-645, 2003.

[36] T. Van Mieghem, E. Eixarch, L. Gucciardo, et al., "Outcome prediction in monochorionic diamniotic twin pregnancies with moderately discordant amniotic fluid," American Journal of Obstetrics and Gynecology, vol. 201, article S38, 2009.

[37] I. H. Linskens, Y. M. de Mooij, J. W. Twisk, W. J. Kist, D. Oepkes, and J. M. van Vugt, "Discordance in nuchal translucency measurements in monochorionic diamniotic twins as predictor of twin-to-twin transfusion syndrome," Twin Research and Human Genetics, vol. 12, no. 6, pp. 605610, 2009.

[38] N. Zosmer, R. Bajoria, E. Weiner, M. Rigby, J. Vaughan, and N. M. Fisk, "Clinical and echographic features of in utero cardiac dysfunction in the recipient twin in twin-twin transfusion syndrome," British Heart Journal, vol. 72, no. 1, pp. 74-79, 1994.

[39] J. D. Pruetz, R. H. Chmait, and M. S. Sklansky, "Complete right heart flow reversal: pathognomonic recipient twin circular shunt in twin-twin transfusion syndrome," Journal of Ultrasound in Medicine, vol. 28, no. 8, pp. 1101-1106, 2009.

[40] T. Van Mieghem, P. Klaritsch, E. Doné et al., "Assessment of fetal cardiac function before and after therapy for twin-totwin transfusion syndrome," American Journal of Obstetrics and Gynecology, vol. 200, no. 4, pp. 400.e1-400.e7, 2009.

[41] J. van den Boom, M. Battin, and T. Hornung, "Twin-twin transfusion syndrome, coarctation of the aorta and hypoplastic aortic arch: a case series report," Journal of Paediatrics and Child Health, vol. 46, no. 3, pp. 76-79, 2010.

[42] D. Mahieu-Caputo, A. Meulemans, J. Martinovic et al., "Paradoxic activation of the renin-angiotensin system in twintwin transfusion syndrome: an explanation for cardiovascular disturbances in the recipient," Pediatric Research, vol. 58, no. 4, pp. 685-688, 2005.

[43] R. Bajoria, S. Ward, and R. Chatterjee, "Natriuretic peptides in the pathogenesis of cardiac dysfunction in the recipient fetus of twin-twin transfusion syndrome," American Journal of Obstetrics and Gynecology, vol. 186, no. 1, pp. 121-127, 2002.

[44] R. Bajoria, S. Ward, and R. Chatterjee, "Brain natriuretic peptide and endothelin-1 in the pathogenesis of polyhydramniosoligohydramnios in monochorionic twins," American Journal of Obstetrics and Gynecology, vol. 189, no. 1, pp. 189-194, 2003.

[45] A. Delabaere, G. Marceau, S. Kemeny et al., "Intra-amniotic $\mathrm{N}$-terminal pro-brain natriuretic peptide in severe twinto-twin transfusion syndrome treated by fetoscopic laser coagulation," Ultrasound in Obstetrics and Gynecology, vol. 35, no. 5, pp. 620-621, 2010. 
[46] K. E. Porter and N. A. Turner, "Cardiac fibroblasts: at the heart of myocardial remodeling," Pharmacology and Therapeutics, vol. 123, no. 2, pp. 255-278, 2009.

[47] Y. Ville, "Twin-to-twin transfusion syndrome: time to forget the Quintero staging system?" Ultrasound in Obstetrics and Gynecology, vol. 30, no. 7, pp. 924-927, 2007.

[48] A. D. Shah, W. L. Border, T. M. Crombleholme, and E. C. Michelfelder, "Initial fetal cardiovascular profile score predicts recipient twin outcome in twin-twin transfusion syndrome," Journal of the American Society of Echocardiography, vol. 21, no. 10, pp. 1105-1108, 2008.

[49] A. Huber, W. Diehl, T. Bregenzer, B.-J. Hackelöer, and K. Hecher, "Stage-related outcome in twin-twin transfusion syndrome treated by fetoscopic laser coagulation," Obstetrics and Gynecology, vol. 108, no. 2, pp. 333-337, 2006.

[50] L. L. Simpson, G. R. Marx, E. A. Elkadry, and M. E. D’Alton, "Cardiac dysfunction in twin-twin transfusion syndrome: a prospective, longitudinal study," Obstetrics and Gynecology, vol. 92, no. 4, pp. 557-562, 1998.

[51] C. Barrea, L. K. Hornberger, F. Alkazaleh et al., "Impact of selective laser ablation of placental anastomoses on the cardiovascular pathology of the recipient twin in severe twintwin transfusion syndrome," American Journal of Obstetrics and Gynecology, vol. 195, no. 5, pp. 1388-1395, 2006.

[52] V. Fesslova, L. Villa, S. Nava, F. Mosca, and U. Nicolini, "Fetal and neonatal echocardiographic findings in twin-twin transfusion syndrome," American Journal of Obstetrics and Gynecology, vol. 179, no. 4, pp. 1056-1062, 1998.

[53] P. H. Gray, C. Ward, and F.-Y. Chan, "Cardiac outcomes of hydrops as a result of twin-twin transfusion syndrome treated with laser surgery," Journal of Paediatrics and Child Health, vol. 45, no. 1-2, pp. 48-52, 2009.

[54] E. Gratacós, D. Van Schoubroeck, E. Carreras et al., "Transient hydropic signs in the donor fetus after fetoscopic laser coagulation in severe twin-twin transfusion syndrome: incidence and clinical relevance," Ultrasound in Obstetrics and Gynecology, vol. 19, no. 5, pp. 449-453, 2002.

[55] E. Eixarch, K. Ty-Torredes, T. Van Mieghem, et al., "Contribution of Doppler and cardiac function evaluation to the prediction of the individualized risk of early fetal demise after laser therapy in twin-twin transfusion syndrome," Ultrasound in Obstetrics and Gynecology, vol. 34, p. 42, 2009.

[56] C. P. Halvorsen, S. L. Bilock, C. Pilo, S.-E. Sonesson, and M. Norman, "Childhood cardiac function after twin-to-twin transfusion syndrome-a 10-year follow up," Acta Paediatrica, International Journal of Paediatrics, vol. 98, no. 9, pp. 14681474, 2009.

[57] Y. F. Cheung, M. J. O. Taylor, N. M. Fisk, A. N. Redington, and H. M. Gardiner, "Fetal origins of reduced arterial distensibility in the donor twin in twin-twin transfusion syndrome," The Lancet, vol. 355, no. 9210, pp. 1157-1158, 2000.

[58] H. M. Gardiner, M. J. O. Taylor, A. Karatza et al., "Twintwin transfusion syndrome: the influence of intrauterine laser photocoagulation on arterial distensibility in childhood," Circulation, vol. 107, no. 14, pp. 1906-1911, 2003.

[59] U. Herberg, W. Gross, P. Bartmann, C. S. Banek, K. Hecher, and J. Breuer, "Long term cardiac follow up of severe twin to twin transfusion syndrome after intrauterine laser coagulation," Heart, vol. 92, no. 1, pp. 95-100, 2006. 


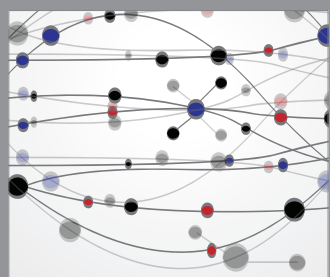

The Scientific World Journal
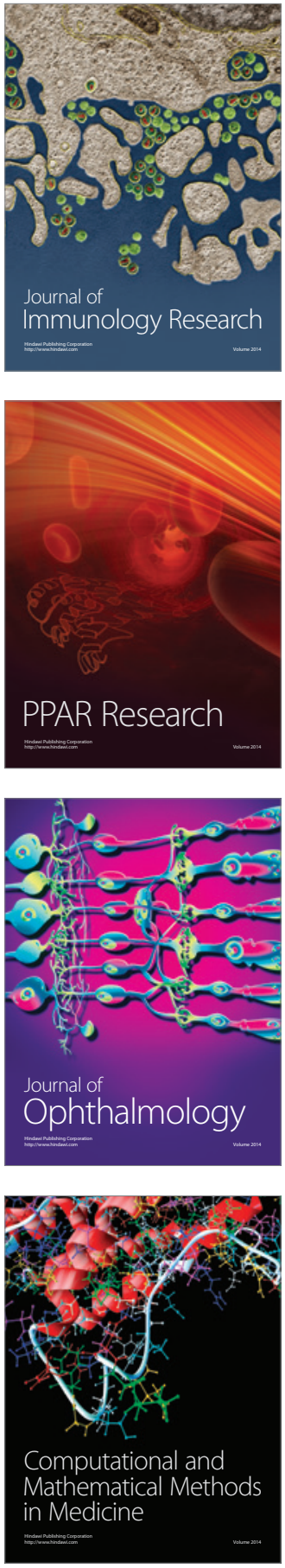

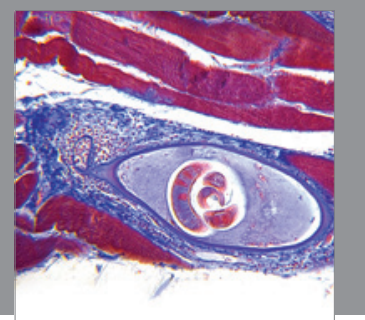

Gastroenterology

Research and Practice
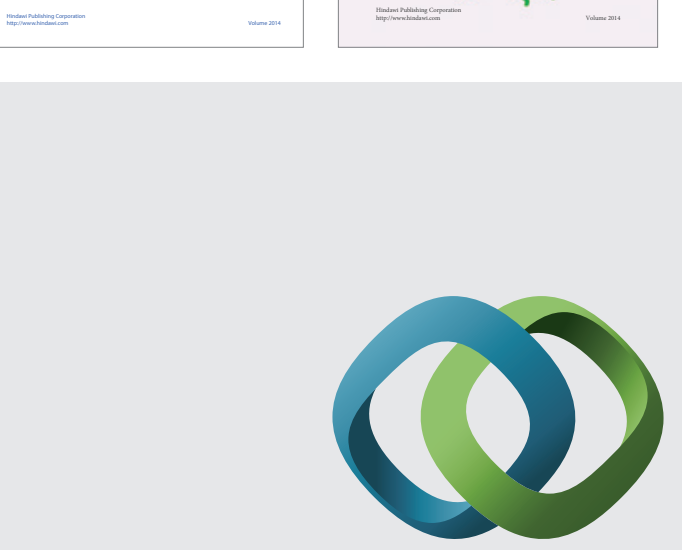

\section{Hindawi}

Submit your manuscripts at

http://www.hindawi.com
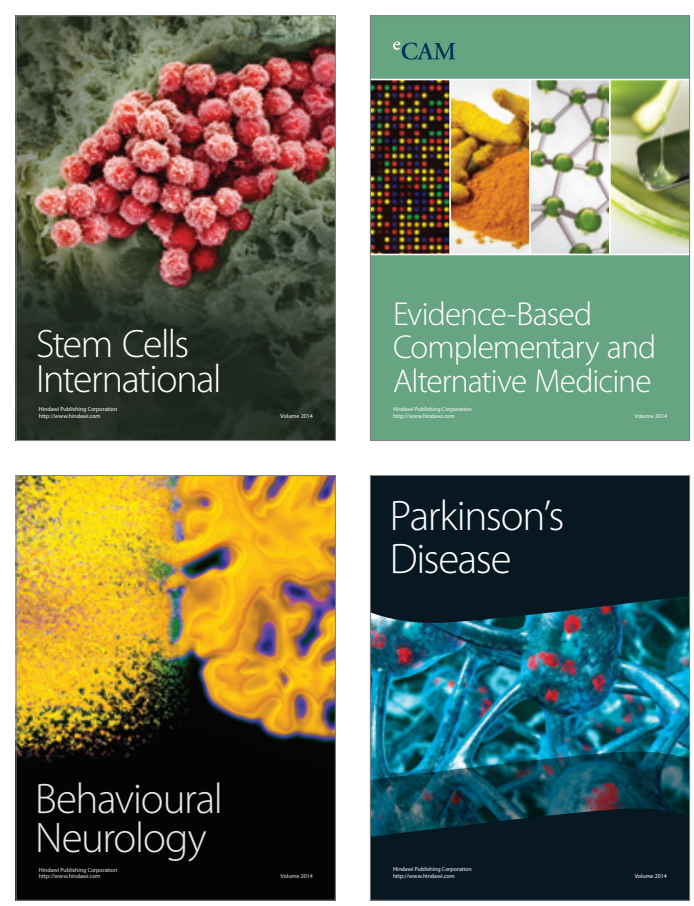

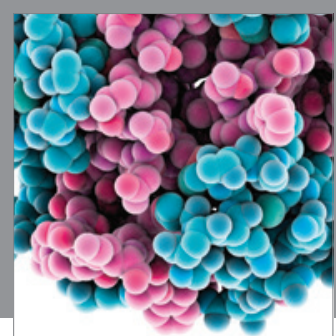

Journal of
Diabetes Research

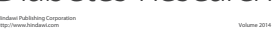

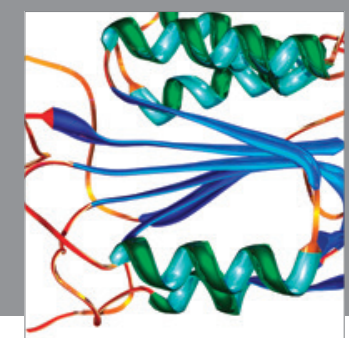

Disease Markers
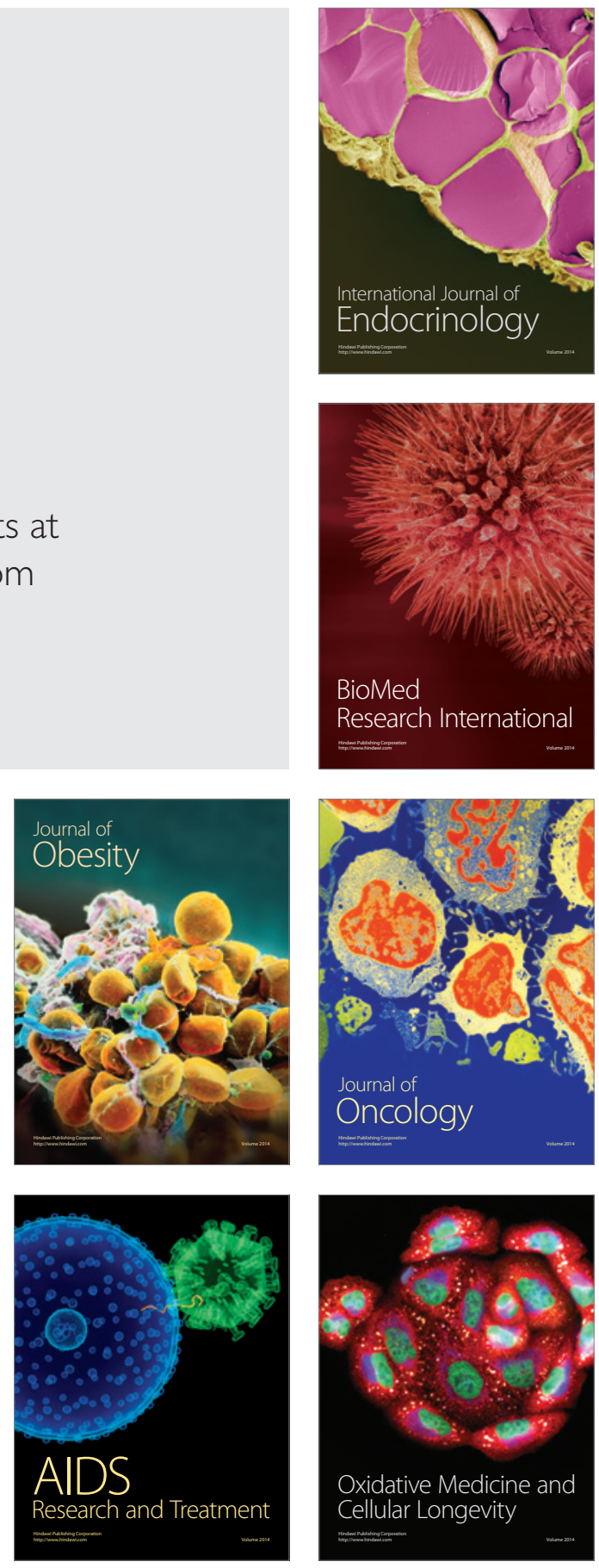